\title{
Research on the Selection of Low Temperature Aluminum Heat Pipe Working Fluid
}

\author{
Yue Yang ${ }^{a}$, Yamei $\mathrm{Li}^{\mathrm{b}}$, Yang $\mathrm{Fu}^{\mathrm{c}}$, Guoyou Xu${ }^{\mathrm{d}}$, Ziyi Zhen ${ }^{\mathrm{e}}$, Yating Wang ${ }^{\mathrm{f}}$, Xiang \\ $\mathrm{Gou}^{\mathrm{g}}$
}

School of Energy and Environmental Engineering, Hebei University of Technology, Tianjin, 300401, China

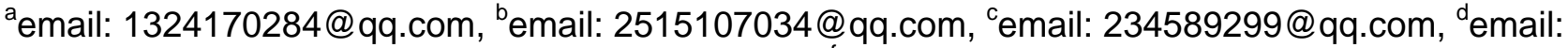
764892290@qq.com, ${ }^{\mathrm{e} e m a i l: 502055568 @ q q . c o m}$, ${ }^{\mathrm{f}}$ email: 1104605586@qq.com, ${ }^{\mathrm{g}}$ Corresponding author email: gouxiang@sina.com

Keywords: heat pipe; heat transfer; working fluid; acetone

\begin{abstract}
Heat pipe is a kind of high efficient heat transfer element, which is widely used in all aspects of life, especially in solar energy technology and permafrost. This research focuses mainly on the low temperature gravity heat pipe working fluid and discusses the influence of refrigerant thermos-physical characteristics to heat transfer. It is shown that the aluminum heat pipe optimal refrigerant is acetone.
\end{abstract}

\section{Introduction}

Heat pipe is a heat transfer components which relies on its phase change to achieve the effect. Due to its high thermal conductivity, excellent isothermal advantages, it is widely used in aerospace and the modern industrial manufacturing field, especially all kinds of heat exchanger and the cooler [1].

There are two types of heat pipe mainly. One is the classic heat pipe, and the other is the gravity heat pipe [2]. The working fluid in the heat pipe absorbs heat from evaporation section and rises to condensation section to emit heat, and then returns to evaporation section by its own gravity. Since the gravity heat pipe is simple in structure, easy to manufacture and low cost and excellent heat transfer performance, it is widely used in the field of heat exchange [3].

The tube shell of the heat pipe works as the role of isolating the working fluid and the environment, so it must be sealed. Because of the near vacuum environment in the pipe, it must withstand the pressure difference between the internal and the external. At the same time, it also cannot react with the working fluid. [4].

\section{The selection of heat pipe working medium}

The heat pipe discussed in this paper is made of aluminum alloy. The selection of the working fluids mainly considers the following questions:

(1) The working fluid should be compatible with the shell material.

(2) The saturation vapor pressure of the working fluid should be suitable at the heat pipe working temperature.

(3)The condensation point and boiling point of the working fluid should be in accordance with the working temperature range of the heat pipe.

(4)The working fluid should have good characteristics of thermal stability, economy, safety and environmental protection.

(5) Working fluid should have good thermal physical properties [5].

The working fluid should be compatible with the shell material. The commonly used working fluids of the heat pipe and the compatible shell materials at different operating temperatures are shown in Table 1 [6]. 
Table 1 Common working fluid of heat pipe

\begin{tabular}{|c|c|c|c|}
\hline Species & Working fluid & $\begin{array}{c}\text { Working } \\
\text { temperature } /{ }^{\circ} \mathrm{C}\end{array}$ & Compatible material \\
\hline $\begin{array}{l}\text { Low } \\
\text { temperature } \\
\text { heat pipe }\end{array}$ & $\begin{array}{l}\text { Ammonia } \\
\mathrm{R}-21\left(\mathrm{CHCl}_{2} \mathrm{~F}\right) \\
\mathrm{R}-11\left(\mathrm{CCl}_{3} \mathrm{~F}\right)\end{array}$ & $\begin{array}{l}-60-100 \\
-40-100 \\
-40-120\end{array}$ & $\begin{array}{c}\text { Aluminum, Stainless steel, } \\
\text { Low-carbon steel } \\
\text { Aluminum, iron } \\
\text { Aluminum, Stainless steel, Copper }\end{array}$ \\
\hline $\begin{array}{c}\text { Normal } \\
\text { temperature } \\
\text { heat pipe }\end{array}$ & $\begin{array}{c}\text { Hexane } \\
\text { Acetone } \\
\text { Ethanol } \\
\text { Methanol } \\
\text { Toluene } \\
\text { Water }\end{array}$ & $\begin{array}{c}0-100 \\
0-120 \\
0-130 \\
10-130 \\
0-290 \\
30-250\end{array}$ & $\begin{array}{c}\text { Brass, Stainless steel } \\
\text { Aluminum, Stainless steel, Copper } \\
\text { Copper, Stainless steel } \\
\text { Copper, Stainless steel } \\
\text { Carbon steel } \\
\text { Stainless steel, Low-carbon steel, } \\
\text { Low-alloy steel } \\
\text { Steel, Carbon steel } \\
\text { (Which inner wall was treated } \\
\text { chemically) }\end{array}$ \\
\hline $\begin{array}{l}\text { Moderate } \\
\text { temperature } \\
\text { heat pipe }\end{array}$ & $\begin{array}{l}\text { Naphthalene } \\
\text { Diphenyl } \\
\text { Dowtherm -A } \\
\text { Dowtherm -E } \\
\text { Mercury }\end{array}$ & $\begin{array}{l}147-350 \\
147-300 \\
150-395 \\
147-300 \\
250-650\end{array}$ & $\begin{array}{c}\text { Aluminum, Stainless steel, } \\
\text { Carbon steel } \\
\text { Stainless steel, Carbon steel } \\
\text { Copper, Stainless steel } \\
\text { Carbon steel } \\
\text { Stainless steel } \\
\text { Carbon steel, Nickel } \\
\text { Austenitic stainless steel }\end{array}$ \\
\hline $\begin{array}{l}\text { High } \\
\text { temperature } \\
\text { heat pipe }\end{array}$ & $\begin{array}{l}\text { Potassium } \\
\text { Cesium } \\
\text { Sodium } \\
\text { Lithium } \\
\text { Silver }\end{array}$ & $\begin{array}{l}400-1000 \\
400-1100 \\
500-1200 \\
1000-1800 \\
1800-2300\end{array}$ & $\begin{array}{c}\text { Stainless steel } \\
\text { Titanium, Niobium } \\
\text { Stainless steel } \\
\text { Kang Ni alloy } \\
\text { Tungsten, Tantalum、 } \\
\text { Molybdenum, Niobium } \\
\text { Tungsten, Tantalum }\end{array}$ \\
\hline
\end{tabular}

Appropriate melting, boiling point, coagulation point and boiling point of working fluids should conform to working temperature range of the heat pipe.

Heat pipe working temperature should between the freezing point and critical point of working fluids . The discussion of this article pays attention to the low temperature heat pipe whose working temperature is $72^{\circ} \mathrm{C}$.

Table 2 Comparison of thermal physical properties of different working fluids

\begin{tabular}{|c|c|c|c|c|}
\hline Working fluids & $\begin{array}{c}25^{\circ} \mathrm{C} \text { Saturated } \\
\text { vapor pressure } / \mathrm{MPa}\end{array}$ & $\begin{array}{c}\text { Atmospheric pressure } \\
\text { boiling point } /{ }^{\circ} \mathrm{C}\end{array}$ & $\begin{array}{c}\text { Working } \\
\text { temperature } /{ }^{\circ} \mathrm{C}\end{array}$ & $\begin{array}{c}\text { Critical } \\
\text { temperature } /{ }^{\circ} \mathrm{C}\end{array}$ \\
\hline Ammonia & 1.00 & -33 & $-60-100$ & ------ \\
\hline R-21 & 0.18 & 8.9 & $-40-100$ & ----- \\
\hline R-11 & 0.11 & 24 & $-40-120$ & ----- \\
\hline Acetone & 0.03 & 57 & $0-120$ & 235.5 \\
\hline Naphthalene & 0.0004 & 217.9 & $147-350$ & ------ \\
\hline HFE7100 & ------ & 61 & ----- & 195.3 \\
\hline PF5060 & 0.03 & 56 & ----- & 177.85 \\
\hline PF5050 & 2.13 & 30 & ----- & 149.85 \\
\hline PF5052 & 0.04 & 50 & ----- & 180.85 \\
\hline XF4310 & 0.03 & 55 & ------ & ----- \\
\hline DR-2 & 0.07 & ------ & ----- & ---- \\
\hline R134a & 0.67 & -26.1 & ----- & 101.1 \\
\hline R113 & 0.045 & 45.7 & ----- & 214.1 \\
\hline
\end{tabular}

At the same time, for the texture of aluminum tube is soft, which leading to the bearing capacity 
of heat pipe also will be affected by certain restrictions. The tube thickness in this paper is $0.9 \mathrm{~mm}$, the diameter of aluminum tube is $22 \mathrm{~mm}$. The formula of the heat pipe maximum working pressure is shown as follows [7]:

$$
[\mathrm{P}]=2[\delta]^{t} s /\left(d_{i}+s\right)
$$

$[\mathrm{P}]-$ Maximum working pressure, $\mathrm{MPa}$

$[\delta]^{\mathrm{t}}$ - Operating temperature material allowable stress, MPa

$\mathrm{s}$ - Wall thickness, mm

$\mathrm{d}_{\mathrm{i}}$ - Pipe diameter, $\mathrm{mm}$

Working fluids should have good thermal stability, economy, safety and green environmental protection. It is found that destruction of R-11and R-21 to the ozonosphere is very serious. Therefore, these two kinds of working fluids are not recommended. Acetone has small influence on environment and it belongs to flammable material. Furthermore, the working temperature of heat pipe is $72^{\circ} \mathrm{C}$ and the highest temperature of the evaporation section is not up to $120^{\circ} \mathrm{C}$. Acetone ignition point is $465^{\circ} \mathrm{C}$. So acetone is appropriate.

For the working fluid in the heat pipe, the liquid phase transmission coefficient is the physical property of heat pipe that should be considered first. Theoretically speaking, the liquid phase transfer coefficient reflects the heat transfer power. Therefore, the greater of the liquid phase transfer coefficient of the working fluids, the more favorable of the heat pipe heat transfer coefficient. The formula of liquid phase transfer coefficient is shown follows [8]:

$$
N_{l}=\sigma \rho_{l} h_{f g} / \mu_{l}
$$

$N_{l}$ - liquid phase transfer coefficient

$\sigma$-Surface tension of working medium, $\mathrm{N} / \mathrm{m}$

$\rho_{l}$ - working fluid density, $\mathrm{kg} / \mathrm{m}^{3}$

$\mu_{l}$-Viscosity, N.S $/ \mathrm{m}^{2}$

$h_{f g}$-Latent heat of vaporization at the operating temperature, $\mathrm{kJ} / \mathrm{kg}$

The liquid phase transfer coefficients of three working fluids at different temperatures are compared in the following figure:

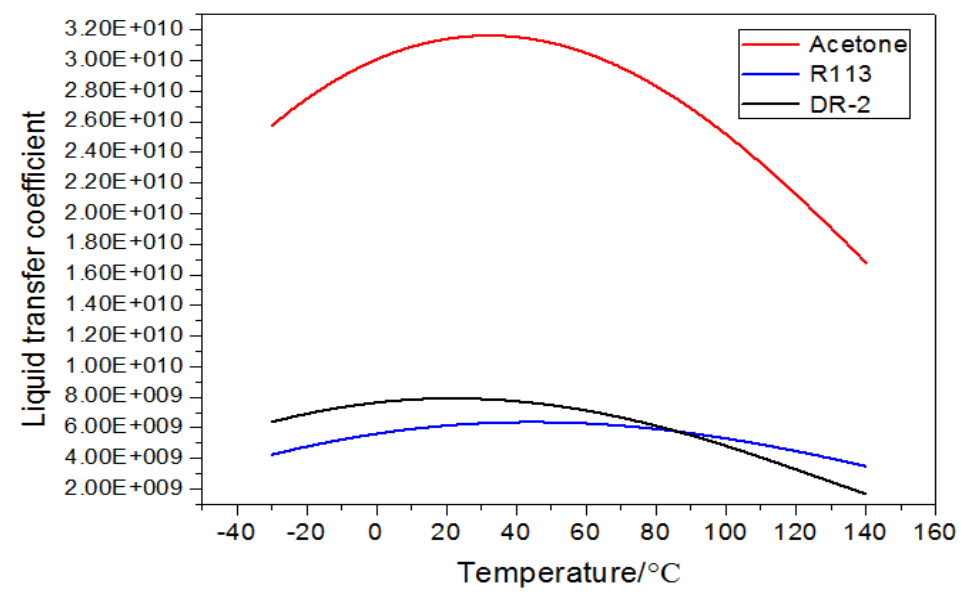

Fig. 1 liquid phase transfer coefficient -temperature curve

It can be seen from the graph, the liquid phase transfer coefficient of different materials has a maximum value. In addition, the liquid phase transmission coefficient of acetone is much larger than R113 and DR-2. The liquid phase transfer coefficient of R113 and DR-2 is almost the same around $83{ }^{\circ} \mathrm{C}$. When the temperature is less than $83{ }^{\circ} \mathrm{C}$, the liquid transmission coefficient of DR-2 is slightly larger than R113.

\section{Advantages of acetone -aluminum heat pipe}

The heat load of heat pipe exchanger is $10 \mathrm{kw}$. Through the design and check of the radiator 
structure, there are 2 cases for choice:

Case 1 . The diameter of heat pipe is $19.27 \mathrm{~mm}$, the single heat pipe heat load is $454.55 \mathrm{~W}$, there are 22 heat pipes in the exchanger;

Case2. The diameter of heat pipe is $19.27 \mathrm{~mm}$, the single heat pipe heat load is $416.67 \mathrm{~W}$, there are 24 heat pipes in the exchanger.

\section{Heat load limit of heat pipe}

The heat load limit-temperature curves are drawn in the Fig. 2.

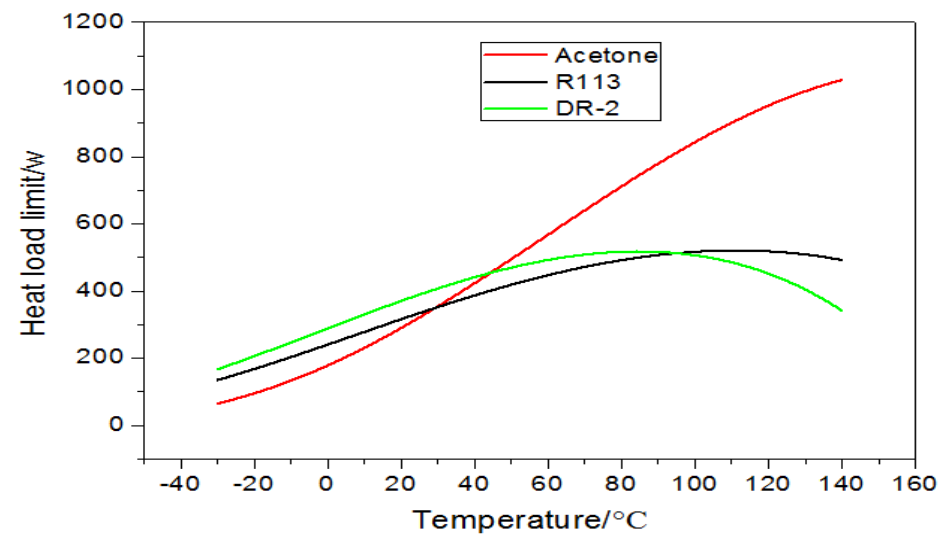

Fig. 2 Heat load limit-temperature curves

It is shown that the acetone heat load increases exponentially with the increase of temperature and is higher than R113 and DR-2, not only because the large evaporation latent heat of acetone, but also the density of the liquid phase and gas phase is less than the other two working fluids at the same temperature.

\section{Carrying limit of heat pipe}

When the heat load of heat pipe increase, the speed of vapor turns large, at the same time the steam and reflux film friction increases, then the liquid working fluid will be carried by the steam flow. This phenomenon hinders the normal flow of condensate and makes the evaporation section over heat, which causes a heat transfer limit [9]. The calculation formula of the carrying limit of the heat pipe is as follows:

$$
d_{c}=\sqrt{\frac{1.78 Q^{\prime \prime}}{\pi \gamma\left(\rho_{l}^{-0.25}+\rho_{v}^{-0.25}\right)^{-2}\left[g \sigma\left(\rho_{l}-\rho_{v}\right)\right]^{0.25}}}
$$

$d_{c}$-Diameter under the carrying limit, $\mathrm{m}$

$Q^{\prime}$ - Heat transfer under the carrying limit, $\mathrm{kW}$

$\gamma$-Latent heat of vaporization, $\mathrm{kJ} / \mathrm{kg}$

$\rho_{l} \rho_{v}$-Vapor - liquid density, $\mathrm{kg} / \mathrm{m}^{3}$

$\sigma$-The liquid surface tension, $\mathrm{N} / \mathrm{m}$

$g$-Acceleration of gravity, $\mathrm{m} / \mathrm{s}^{2}$ 


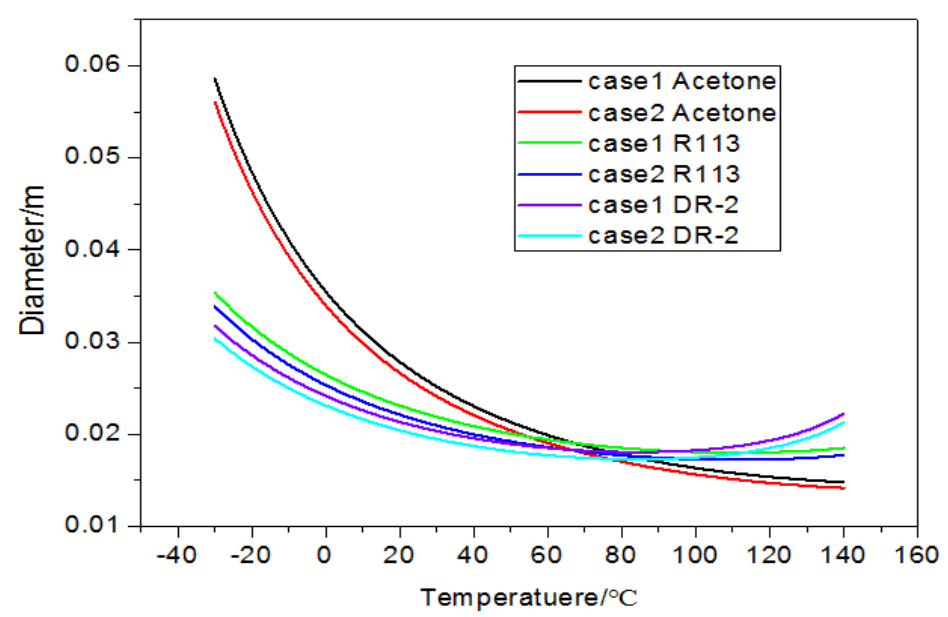

Fig. 3 Diameter-temperature curves under the carrying limit

The diameter of heat pipe is limited by carrying limit, which requires the design diameter should be bigger than the carrying limit's. Fig. 3 shows when the temperature is below $60^{\circ} \mathrm{C}$, the heat pipe diameter under the carrying limit of acetone is bigger than the other two working fluids. While the temperature is over $60^{\circ} \mathrm{C}$, with the increasing of temperature, the diameter of heat pipe under the carrying limit is less than the other two substances. For the heat pipe with operation temperature at $72^{\circ} \mathrm{C}$ acetone should be selected as working fluid.

\section{Speed of sound limit of heat pipe}

The designing value of the heat pipe diameter should more than the speed of sound limit under the working temperature. The speed of sound limit is calculated as follows:

$$
d_{v}=1.64 \sqrt{\frac{Q_{c}}{\gamma\left(P_{v} \rho_{v}\right)^{0.5}}}
$$

$d_{v}$-Diameter of steam flow cross section, $\mathrm{m}$

$\rho_{v}$-Density of vapor in the pipe, $\mathrm{kg} / \mathrm{m}^{3}$

$P_{v}$ - Pressure of steam in pipe, $\mathrm{Pa}$

$\gamma$-Latent heat of vaporization, $\mathrm{kJ} / \mathrm{kg}$

$Q_{c}$ - Heat transfer under the speed of sound limit, $\mathrm{kW}$

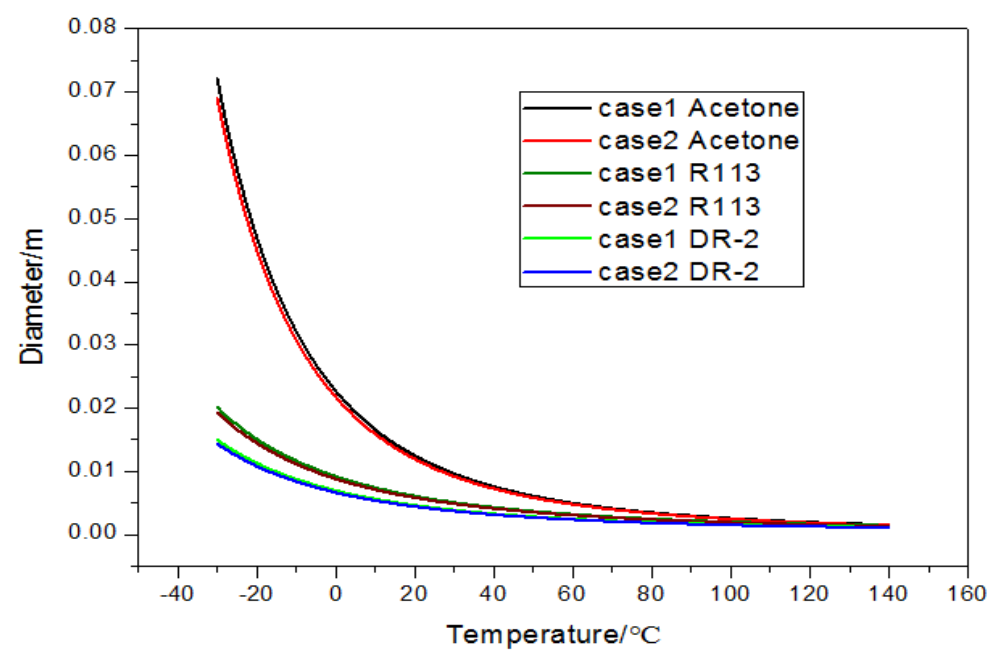

Fig. 4 Diameter- temperature curve under the speed of sound velocity limit

Fig.4 shows that the diameter of the speed of sound limit reduces with the temperature increase in the three kinds of working fluids. After the temperature is below $100^{\circ} \mathrm{C}$, the speed of sound limit of acetone is more than the other two fluids'. Moreover, the diameter of the speed of 
sound limits are gradually stabilized over $100^{\circ} \mathrm{C}$. At the same time, the diameter of carrying limit is more than the speed of sound limit at the same temperature of a working fluid.

\section{Conclusions}

Taking the design principles of heat pipe into account, acetone is not only compatible with aluminum, but also in line with the design principles of heat pipes in other aspects. Moreover, large amounts of data show that acetone has more advantages than R113 and DR-2 for aluminum heat pipe. However acetone is extremely flammable and poisonous substances, it should be careful in the process of filling heat pipe. Many studies are looking for a new working fluid to instead of acetone, while the effect of heat transfer is not verified.

\section{References}

[1] Bin Fang, Wenbin Bai. Energy-saving heat pipe exchanger of boilers and furnaces[M]. Harbin: Harbin Institute of Technology Press, 1985, 57-59.

[2] Jun Zhuang, Hong Zhang. Heat Pipe Technology and Engineering Application[M].Beijing: Chemical Industry Press,2000(5) , 50-60.

[4] M.N. Ivanovski, V.P. Sorokin, I.V.Yagedejin.Thermal physicial principle of heat pipe[M].Beijng: China Petrochemical Press, 1987, 12-25.

[5] S.W.Ji. Heat pipe theory and Practice[M]. Yanzhang Jiang translate. Science Press.Beijing. 1981, 92-96.

[6] Hongjun You. Progress in application of heat pipe technology [J]. Sichuan Chemical Industry, 2005, 5(3) ,47-50.

[7] Gang Liu. Working fluid selection of gravity heat pipe[J] . Refrigeration and Air Conditioning (Sichuan), 2006,(1), 41-43.

[8] Guiyun Li, Jin Tu. High temperature heat pipe working medium selection [J]. Energy-saving technology , 2001 ,43-45.

[9]Lei Wang. The design and calculation of heat pipe exchanger [J]. Soda Industry, 2001,(3) ,39-41. 